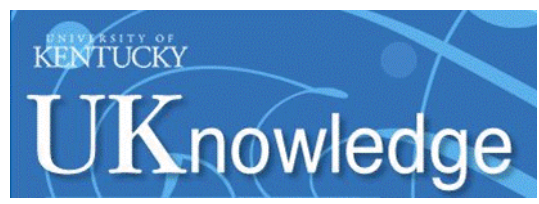

University of Kentucky

UKnowledge

Pharmacy Practice and Science Faculty

Publications

Pharmacy Practice and Science

$12-9-2021$

\title{
Major Publications in the Critical Care Pharmacotherapy Literature: 2020
}

\author{
Brittany D. Bissell \\ University of Kentucky, brittany.bissell@uky.edu \\ Jeannee Campbell \\ University of Texas MD Anderson Cancer Center \\ Reagan Collins \\ University of Texas MD Anderson Cancer Center \\ Charles Cook \\ Beth Israel Deaconess Medical Center \\ Dharati Desai \\ Advocate Christ Medical Center
}

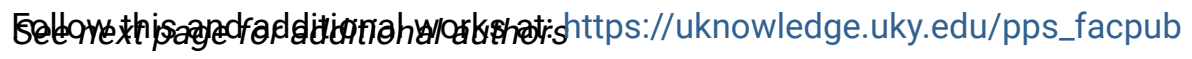

Part of the Pharmacy and Pharmaceutical Sciences Commons

Right click to open a feedback form in a new tab to let us know how this document benefits you.

\section{Repository Citation}

Bissell, Brittany D.; Campbell, Jeannee; Collins, Reagan; Cook, Charles; Desai, Dharati; DeWitt, Jessica; Eche, Ifeoma Mary; Eche, ljeoma Julie; Elsamadisi, Pansy; Juul, Janelle; Kim, Soyoung; Makowski, Courtney T.; Mylvaganam, Ruben J; Smith, Adam; Stancati, Jennifer; Stonesifer, Katherine; Tawil, Justin; and Smith Condeni, Melanie, "Major Publications in the Critical Care Pharmacotherapy Literature: 2020" (2021). Pharmacy Practice and Science Faculty Publications. 72.

https://uknowledge.uky.edu/pps_facpub/72

This Review is brought to you for free and open access by the Pharmacy Practice and Science at UKnowledge. It has been accepted for inclusion in Pharmacy Practice and Science Faculty Publications by an authorized administrator of UKnowledge. For more information, please contact UKnowledge@lsv.uky.edu. 


\title{
Major Publications in the Critical Care Pharmacotherapy Literature: 2020
}

\author{
Digital Object Identifier (DOI)
}

https://doi.org/10.1097/cce.0000000000000590

\section{Notes/Citation Information}

Published in Critical Care Explorations, v. 3, issue 12, e0590.

Copyright (c) 2021 The Authors

This is an open-access article distributed under the terms of the Creative Commons Attribution-Non Commercial-No Derivatives License 4.0 (CCBY-NC-ND), where it is permissible to download and share the work provided it is properly cited. The work cannot be changed in any way or used commercially without permission from the journal.

\section{Authors}

Brittany D. Bissell, Jeannee Campbell, Reagan Collins, Charles Cook, Dharati Desai, Jessica DeWitt, Ifeoma Mary Eche, ljeoma Julie Eche, Pansy Elsamadisi, Janelle Juul, Soyoung Kim, Courtney T. Makowski, Ruben J Mylvaganam, Adam Smith, Jennifer Stancati, Katherine Stonesifer, Justin Tawil, and Melanie Smith Condeni 


\section{Major Publications in the Critical Care Pharmacotherapy Literature: 2020}

OBJECTIVES: To summarize selected meta-analyses and trials related to critical care pharmacotherapy published in 2020.

DATA SOURCES: The Clinical Pharmacy and Pharmacology Pharmacotherapy Literature Update group screened 36 journals monthly for impactful publications.

STUDY SELECTION: The group reviewed a total of 119 articles during 2020 according to relevance for practice.

DATA EXTRACTION: Articles were selected with consensus and importance to clinical practice from those included in the monthly Clinical Pharmacy and Pharmacology Pharmacotherapy Literature Update. The group reviewed articles according to Grading of Recommendations, Assessment, Development, and Evaluations criteria. Articles with a $1 \mathrm{~A}$ grade were selected.

DATA SYNTHESIS: Several trials were summarized, including two meta-analyses and five original research trials. Original research trials evaluating vitamin $\mathrm{C}$, hydrocortisone, and thiamine versus hydrocortisone in sepsis, the use of nonsedation strategies, dexmedetomidine in cardiac surgery, remdesivir for severe acute respiratory syndrome coronavirus 2 , and thrombectomy in acute ischemic stroke. Two meta-analyses determining the impact of norepinephrine initiation in patients with septic shock and the use of corticosteroids in severe acute respiratory syndrome coronavirus 2 was included.

CONCLUSIONS: This clinical review provides summary and perspectives of clinical practice impact on influential critical care pharmacotherapy publications in 2020.

KEY WORDS: coronavirus disease 2019; critical care; drug therapy; review; sedation; septic shock

ritical care practitioners commit significant time staying up-to-date with the most pertinent medical literature (1). As such, clinicians rely on electronic table of contents, social media, blogs, and article synopses to provide a summary of relevant literature (2). In 2009, a group of critical care pharmacists developed a process for updating practitioners on new critical care pharmacotherapy literature resulting in the Clinical Pharmacy and Pharmacology Pharmacotherapy Literature Update (CPPPLU), a monthly publication summarizing new literature. Currently, under the Clinical Pharmacy and Pharmacology (CPP) Section of the Society of Critical Care Medicine (SCCM), monthly reviews continue with annual review of the most impactful literature for the year (3-6).

\section{MATERIALS AND METHODS}

Monthly, the CPPPLU workgroup evaluates and selects articles relevant to critical care practice systematically from 36 journals based on importance and relevance to practice (Appendix A). For inclusion, articles must meet the following criteria: 1) controlled trial, observational, meta-analysis or major
Brittany D. Bissell, PharmD, PhD, BCCCP1

Jeannee Campbell, $\mathrm{PA}^{2}$

Reagan Collins, PharmD, BCCCP ${ }^{3}$

Charles Cook, MD, FCCM ${ }^{4}$

Dharati Desai, PharmD, BCCCP 5

Jessica DeWitt, BSN, RN, CCRN ${ }^{6}$

Ifeoma Mary Eche, PharmD, BCPS, BCCCP, CACP 4

ljeoma Julie Eche, PhD, FNP-BC, AOCNP, BMT-CN, CPHON ${ }^{4}$

Pansy Elsamadisi, PharmD, BCPS, BCCCP ${ }^{4}$

Janelle Juul, PharmD, BCCCP7

Soyoung Kim, PharmD, BCCCP

Courtney T. Makowski, PharmD, $\mathrm{BCCCP}^{9}$

Ruben J. Mylvaganam, MD $^{10}$

Adam Smith, PharmD, BCPS, $\mathrm{BCCCP}^{6}$

Jennifer Stancati, MD ${ }^{5}$

Katherine Stonesifer, CRNP ${ }^{8}$

Justin Tawil, MD ${ }^{7}$

Melanie Smith Condeni, PharmD, BCPS, BCCCP ${ }^{11}$

Copyright (c) 2021 The Authors. Published by Wolters Kluwer Health, Inc. on behalf of the Society of Critical Care Medicine. This is an open-access article distributed under the terms of the Creative Commons AttributionNon Commercial-No Derivatives License 4.0 (CCBY-NC-ND), where it is permissible to download and share the work provided it is properly cited. The work cannot be changed in any way or used commercially without permission from the journal.

DOI: $10.1097 / C C E .0000000000000590$ 
guideline/guideline update; 2) adult patient population; 3) addresses critical care and involving drug therapy (including fluid and nutritional therapy, drugimpregnated lines, and dialysis in the ICU or percutaneous coronary interventions); and 4) published in current monthly issue. Articles that do not meet such criteria and those that are published online ahead-ofprint are excluded. CPPPLU members are assigned journals for monthly evaluation and abstraction and assign a Grading of Recommendations, Assessment, Development, and Evaluations (GRADE) score upon extraction (7). Currently, the CPPPLU is distributed globally to the membership of SCCM through a webbased platform and social media. From 119 articles reviewed in 2020, articles that were GRADE 1A were evaluated for annual review. Articles that appeared to have high impact were selected in addition to consideration for breadth of critical care medication category and specialty pertinence. All authors agreed with selected content and the article as well as its content were approved by the SCCM CPP Steering Committee and SCCM Council.

\section{RESULTS}

Over the course of the year, 26 articles were analyzed for inclusion into this article. Two meta-analyses and five clinical research trials were selected for review for this annual publication on the basis of GRADE criteria (1A), pharmacotherapeutic focus, and expected practice influence (8-13). Table 1 provides a summary of the studies selected for discussion.

\section{DISCUSSION}

\section{Coronavirus Disease 2019}

Remdesivir in Adults With Severe Coronavirus Disease 2019: A Randomized, Double-Blind, PlaceboControlled, Multicenter Trial. This randomized, placebo-controlled, double-blind trial evaluated remdesivir $200 \mathrm{mg}$ on day one followed by $100 \mathrm{mg}$ daily on days $2-10$ in hospitalized adults with severe, laboratory-confirmed coronavirus disease 2019 (COVID-19) pneumonia (11). Those exhibiting oxygen saturation of less than or equal to $94 \%$ on room air or an $\mathrm{PaO}_{2}$ to $\mathrm{FiO}_{2}$ ratio of less than or equal to $300 \mathrm{~mm} \mathrm{Hg}$ within 12 days of symptom onset were included. Median time from symptom onset to treatment randomization was 10 days. The majority of patients were categorized at baseline as a "three" on 6-point clinical status ordinal scale ( $\operatorname{six}=$ death, three $=$ hospitalized with supplemental oxygen, one = discharge eligible). The trial was terminated early due to control of the outbreak in Wuhan, reducing statistical power from $80 \%$ to $58 \%(n-237)$.

In the intention to treat analysis, remdesivir showed no difference in time to clinical improvement ( $21 \mathrm{~d}$ vs 23 $\mathrm{d}$; hazard ratio, 1.23 ; $95 \% \mathrm{CI}, 0.87-1.75)$ or 28 -day mortality (14\% vs $13 \%$; difference, $1.1 \%$; CI, -8.1 to 10.3 ). Those receiving remdesivir within 10 days of symptom onset exhibited a numerically faster time to clinical improvement and numerically higher clinical improvement rates at days 14 and 28. Ultimately, remdesivir conferred no statistical difference in either clinical improvement or mortality compared with placebo, although severely underpowered due to early termination.

Numerous trials have evaluated remdesivir for COVID-19 displaying similar results. The Adaptive COVID-19 Treatment Trial-1 study demonstrated significantly reduced time to recovery (10 vs 15 d; recovery rate ratio [RR], 1.29; 95\% CI, $1.12-1.49 ; p<0.001)$ and higher clinical improvement scores at day 15 (odds ratio [OR], 1.5; 95\% CI, $1.2-1.9 ; p<0.001$ ) with remdesivir (15). Specifically, the subgroup of patients requiring supplemental oxygen (not via means of high-flow nasal cannula or noninvasive ventilation) and those receiving treatment less than 10 days from symptom onset gleaning the most benefit. The World Health Organization (WHO) Solidarity trial compliments this, finding no mortality benefit (RR, 0.95 ; 95\% CI, 0.81-1.11; $p=0.50$ ), but numerically lower deaths in lower risk patients not requiring ventilation ( $R R, 0.80 ; 95 \% \mathrm{CI}, 0.63-1.01)$ (16). Aforementioned trials included 10-day remdesivir courses; however, studies evaluating 5- and 10-day courses revealed no difference in clinical status or improvement between the two durations $(17,18)$.

Wang et al (11), combined with available literature, may suggest a role for 5 days of remdesivir in low-risk, hospitalized patients receiving noninvasive oxygenation within 10 days of symptom onset to prevent risk of deterioration. Remdesivir may curtail duration of illness, expediting time to hospital discharge, which could greatly impact limited healthcare resources. Current guidelines recommend against its use in patients on invasive ventilation or extracorporeal membrane oxygenation (19). 
TABLE 1.

Article Summary

\begin{tabular}{|c|c|c|c|c|}
\hline References & Population & Intervention & Design & Outcomes \\
\hline Fujii et al (8) & $\begin{array}{l}\text { Two-hundred eleven patients } \\
\text { with septic shock, } \\
\text { vasopressor dependent } \\
\text { for at least } 2 \mathrm{hr}\end{array}$ & $\begin{array}{l}\text { Vitamin } \mathrm{C} \\
\text { hydrocortisone, } \\
\text { thiamine vs } \\
\text { placebo }\end{array}$ & $\begin{array}{l}\text { Multicenter, } \\
\text { open-label, } \\
\text { parallel-group, } \\
\text { randomized } \\
\text { controlled }\end{array}$ & $\begin{array}{l}\text { No difference in time alive and free of } \\
\text { vasopressors at day } 7\end{array}$ \\
\hline Li et al (13) & $\begin{array}{l}\text { Nine-hundred twenty-nine } \\
\text { adult patients with septic } \\
\text { shock }\end{array}$ & $\begin{array}{l}\text { Early vs later } \\
\text { norepinephrine } \\
\text { initiation }\end{array}$ & Meta-analysis & $\begin{array}{l}\text { Short-term mortality was lower with } \\
\text { early norepinephrine group } \\
\text { High heterogeneity }\end{array}$ \\
\hline $\begin{array}{l}\text { Olsen } \\
\text { et al (9) }\end{array}$ & $\begin{array}{l}\text { Seven-hundred ten } \\
\text { mechanically ventilated } \\
\text { patients }\end{array}$ & $\begin{array}{l}\text { Light sedation vs } \\
\text { nonsedation }\end{array}$ & $\begin{array}{l}\text { Multicenter, } \\
\text { randomized, } \\
\text { nonblinded } \\
\text { study }\end{array}$ & $\begin{array}{l}\text { No difference in all-cause } 90-d \\
\text { mortality, delirium-free days, } \\
\text { mechanical ventilation duration }\end{array}$ \\
\hline $\begin{array}{l}\text { Turan } \\
\text { et al (10) }\end{array}$ & $\begin{array}{l}\text { Seven-hundred ninety-eight } \\
\text { adult patients undergoing } \\
\text { cardiac surgery with } \\
\text { cardiopulmonary bypass and } \\
\text { heart rate }>50 \text { beats } / \mathrm{min}\end{array}$ & $\begin{array}{l}\text { Dexmedetomidine } \\
\text { vs placebo }\end{array}$ & $\begin{array}{l}\text { Multicenter, } \\
\text { randomized }\end{array}$ & $\begin{array}{l}\text { No difference in postoperative atrial } \\
\text { fibrillation } \\
\text { Increase in clinically significant } \\
\text { hypotension with dexmedetomidine }\end{array}$ \\
\hline $\begin{array}{l}\text { Rapid Evidence } \\
\text { Appraisal for } \\
\text { COVID-19 } \\
\text { Therapies } \\
\text { (REACT) } \\
\text { Working } \\
\text { Group et al } \\
\text { (14) }\end{array}$ & $\begin{array}{l}\text { One-thousand seven- } \\
\text { hundred three critically ill } \\
\text { patients with COVID-19 }\end{array}$ & $\begin{array}{l}\text { Corticosteroids vs } \\
\text { placebo }\end{array}$ & $\begin{array}{l}\text { Meta-analysis of } \\
\text { randomized } \\
\text { trials }\end{array}$ & $\begin{array}{l}\text { Decreased } 28 \text {-d mortality with } \\
\text { steroids } \\
\text { Minimal heterogeneity reported, but } \\
\text { several corticosteroid regimens } \\
\text { used }\end{array}$ \\
\hline $\begin{array}{l}\text { Wang } \\
\text { et al (11) }\end{array}$ & $\begin{array}{l}\text { Two-hundred thirty-seven } \\
\text { adults with severe, } \\
\text { laboratory-confirmed } \\
\text { COVID-19 pneumonia }\end{array}$ & $\begin{array}{l}\text { Remdesivir vs } \\
\text { placebo }\end{array}$ & $\begin{array}{l}\text { Randomized, } \\
\text { double-blind trial }\end{array}$ & $\begin{array}{l}\text { No difference in time to clinical } \\
\text { improvement or mortality }\end{array}$ \\
\hline $\begin{array}{l}\text { Yang } \\
\text { et al (12) }\end{array}$ & $\begin{array}{l}\text { Six-hundred fifty-six } \\
\text { adults with large vessel } \\
\text { occlusion and National } \\
\text { Institute of Health Stroke } \\
\text { Scale of at least two }\end{array}$ & $\begin{array}{l}\text { Thrombectomy } \\
\text { alone vs in } \\
\text { combination } \\
\text { with alteplase }\end{array}$ & $\begin{array}{l}\text { Prospective, } \\
\text { randomized, } \\
\text { open-label trial }\end{array}$ & $\begin{array}{l}\text { Modified Rankin score at } 90 \mathrm{~d} \\
\text { with thrombectomy alone vs } \\
\text { combination was noninferior } \\
\text { No difference in mortality, severe } \\
\text { adverse events, or procedural } \\
\text { complications }\end{array}$ \\
\hline
\end{tabular}

COVID-19 = coronavirus disease 2019.

WHO Rapid Evidence Appraisal for COVID-19 Therapies (REACT) Working Group et al. Administration of Systemic Corticosteroids and Mortality Among Critically Ill Patients With COVID-19: A Meta-Analysis. The use of corticosteroids for the treatment of viral pneumonias has been a widely debated controversy (14). Prior to the publication of studies evaluating its effect in severe acute respiratory syndrome coronavirus 2 (SARS-CoV-2), practice guidelines from multiple organizations cautioned against the routine use of corticosteroids in patients with COVID-19 pneumonia (20). This recommendation was largely based on experiences with other viruses such as influenza, SARS-CoV, and Middle East respiratory syndrome coronavirus, in which corticosteroids have been associated with delayed viral clearance and worse clinical outcomes $(21,22)$. However, corticosteroids became standard practice for the treatment of COVID19 pneumonia after the publication of the Randomized Evaluation of COVID-19 Therapy (RECOVERY) trial that suggested a mortality benefit (23). 
The WHO Rapid Evidence Appraisal for COVID-19 Therapies (REACT) Working Group conducted a prospective meta-analysis of randomized trials to estimate the association between corticosteroids versus usual care or placebo and 28-day all-cause mortality in hospitalized, critically ill patients with COVID-19 (14). Trials were identified by trial registries until April 2020 and data were pooled from patients recruited to trials by June 9,2020 . Patients recruited after the release of the results of the RECOVERY trial were not included in the analysis. Of 16 trials identified, seven were included in the final meta-analysis with 1,703 critically ill patients (678 to corticosteroids and 1,025 to usual care/ placebo). Corticosteroid therapies included low and high-dose dexamethasone (three studies), low-dose hydrocortisone (three studies), and high-dose methylprednisolone (one study). A majority of patients were on mechanical ventilation (91.5\%), and $47 \%$ were on vasoactive agents at randomization. Five trials reported mortality at 28 days, one at 21 days, and one at 30 days.

The primary outcome, all-cause mortality at 28 days, was lower in the steroid arm compared with the no steroid arm based on a fixed-effect meta-analysis $(32.7 \%$ vs $41.5 \%$; OR, 0.66; 95\% CI, 0.53-0.82; $p<0.001)$. Dexamethasone was associated with lower all-cause mortality (OR, 0.64; 95\% CI, 0.50-0.82; $p<0.001$ ), whilehydrocortisone(OR, 0.69;95\% CI, 0.43$1.12 ; p=0.13)$ and methylprednisolone (OR, $0.91 ; 95 \%$ CI, $0.29-2.87 ; p=0.87$ ) were not. In subgroup analyses, among patients receiving invasive mechanical ventilation, the OR for mortality associated with corticosteroids compared with usual care was 0.69 (95\% CI, $0.55-0.86)$ and among those that were not on invasive ventilation, the $\mathrm{OR}$ was 0.41 (95\% CI, 0.19-0.88). There was also a stronger association between corticosteroids and lower mortality in patients who were not receiving vasoactive medications (OR, 0.55 ; 95\% CI, 0.34-0.88) than those who were (OR, 1.05; 95\% CI, 0.65-1.69).

The authors concluded that corticosteroid administration was associated with a lower all-cause mortality without evidence suggesting an increased risk of serious adverse events (14). The analysis reports minimal heterogeneity with $I^{2}$ of $15.6 \%(p=0.31)$; however, the included trials had substantial differences in the definition of illness, steroid choice and dose, duration of therapy, and reporting of adverse events. Particularly, the three steroids used have different durations of activity, dosing strategies, and potency of mineralocorticoid or glucocorticoid activities. The RECOVERY trial, which used low-dose dexamethasone, contributed $57 \%$ of the weight in the primary outcome of allcause mortality. In contrast, only one study evaluated the effect of methylprednisolone and contributed 3.5\% of the weight in the primary analysis. Given the high percentage of patients receiving dexamethasone in this analysis, the mortality benefit of alternative steroids, such as methylprednisolone remains to be determined. Uncertainties remain in regards to appropriate dosing and duration of corticosteroids in different severities of critical illness or ventilatory support, as well as the additive effect of adjunctive therapies for COVID-19 such as remdesivir.

\section{Sepsis and Septic Shock}

Effect of Vitamin C, Hydrocortisone, and Thiamine Versus Hydrocortisone Alone on Time Alive and Free of Vasopressor Support Among Patients With Septic Shock (VITAMINS). The VITAMINS trial was a multicenter,open-label,parallel-group, randomized controlled trial (RCT) evaluating resolution of shock with vitamin C ( $1.5 \mathrm{~g}$ every $6 \mathrm{hr}$ ), hydrocortisone (50 mg every $6 \mathrm{hr}$ ), and thiamine (200 mg every $12 \mathrm{hr}$ ) (HAT) therapy (8). Patients in septic shock who were vasopressor dependent for at least 2 hours were randomized to HAT therapy ( $n=107)$ versus the control group of hydrocortisone alone $(n=104)$ with treatment durations until shock resolution or up to 10 days.

Baseline characteristics were similar between groups, except the HAT therapy group had numerically higher lactate levels (median, 4.2 vs $3.3 \mathrm{mmol} / \mathrm{L}$ ). Mean baseline Sequential Organ Failure Assessment (SOFA) scores were similar in the HAT and control groups (8.6 vs 8.4 , respectively). There was no difference in the primary outcome of time alive and free of vasopressors at day 7 (median $122.1 \mathrm{vs} 124.6 \mathrm{hr}$ in HAT therapy vs control group, respectively; $p=0.83$ ) or 28 - and 90-day mortality. The change in SOFA score was significantly greater with HAT therapy at day 3 compared with the control group (median -2 vs $-1 ; p=0.02$ ). The mean duration of either therapy was 3.4 days.

In 2017, Marik et al (24) observed a significant reduction in duration of vasopressor use and hospital mortality in patients with severe sepsis or septic shock who received HAT therapy versus standard of care. This set forth several trials evaluating the impact of HAT combination on morbidity and mortality outcomes, each with slightly different study designs. The 
VITAMINS study, which only enrolled septic shock patients with the control arm receiving hydrocortisone, disputed the Marik et al (24) findings, as there was no difference in the primary outcome or secondary outcomes of 28- and 90-day mortality (8). The improvement in SOFA score at day 3 in the HAT therapy group was not corroborated in two additional studies at 4 days and 72 hours, respectively $(8,25,26)$. Both the Outcomes of Metabolic Resuscitation Using Ascorbic Acid, Thiamine, Glucocorticoids in the Early Treatment of Sepsis (ORANGES) and Ascorbic Acid, Corticosteroids, and Thiamine in Sepsis (ACTS) trials found faster time to resolution of shock in the HAT therapy group versus placebo, unlike the VITAMINS trial $(25,26)$. However, there is well-established evidence that the use of hydrocortisone reduces time to resolution of shock and only $41 \%$ and $14 \%$ of patients in the placebo arms of the ORANGES and ACTS trials received corticosteroids, respectively $(27,28)$. Current available evidence does not support the routine use of HAT therapy over hydrocortisone alone for resolution of shock or for improvement of mortality in patients with sepsis.

Timing of Norepinephrine Initiation in Patients With Septic Shock: A Systematic Review and Meta-Analysis. In the systematic review and meta-analysis conducted by Li et al (13), early norepinephrine use was compared with late initiation of norepinephrine in patients with septic shock. A random-effects model was used to pool studies with significant heterogeneity. Five studies with a combined sample size of 929 adult patients were included (29-32). The five studies were analyzed for the primary endpoint of short-term mortality. Short-term mortality was defined as hospital, 28-day, and 30-day mortality. Three (60\%) of the included studies were analyzed for these secondary outcomes: ICU length of stay, time to achieve target mean arterial pressure (MAP), and volume of IV fluids (IVFs) within 6 hours (29-32).

While there was no significant heterogeneity found among the studies for short-term mortality $\left(I^{2}=0 \%\right)$, ICU length of stay $\left(I^{2}=0 \%\right)$, and time to target MAP $\left(I^{2}=0 \%\right)$, there was substantial heterogeneity present for volume of IVF within 6 hours $\left(I^{2}=94 \%\right)$. Short-term mortality was lower in the early norepinephrine group compared with the late norepinephrine group (OR, 0.45; 95\% CI, 0.34-0.61). There was no significant difference in ICU length of stay (mean difference $=-0.11 \mathrm{~d} ; 95 \%$ $\mathrm{CI},-1.27$ to 1.05$)$. However, the early norepinephrine group had shorter time to target MAP (mean difference $=-1.39 \mathrm{hr} ; 95 \% \mathrm{CI},-1.81$ to $-0.96 \mathrm{hr})$ and used less IVF within 6 hours (mean difference $=-0.50 \mathrm{~L} ; 95 \%$ CI, -0.68 to $-0.32 \mathrm{~L}$ ).

Norepinephrine remains the first-line vasopressor for septic shock (33). Although the surviving sepsis guidelines recommend use of vasopressors early in the course of septic shock, the impact on clinical outcomes remains unclear (34). The 2018 update to the Surviving Sepsis Guidelines recommends rapid administration of crystalloid within the first hour of septic shock and early application of vasopressors in patients who remain hypotensive despite fluid resuscitation (34). Consistent with the guidelines, the findings of this meta-analysis support the use of norepinephrine early in the course of septic shock. Early administration of norepinephrine shortens the duration of hypotension and provides adequate perfusion to prevent organ damage (34). Additionally, the use of vasopressors early may minimize the use of unnecessary fluids beyond the initial resuscitation period.

Although the aforementioned guideline recommendations for early vasopressor initiation are part of the 1-hour sepsis bundle, the most optimal timing is still unclear. The studies included in this meta-analysis had variable definitions of early versus late vasopressor administration. The definitions of early norepinephrine ranged from prior to fluid resuscitation to less than 6 hours from onset of septic shock. As fluid overload is associated with increased mortality, future studies should better delineate a more explicit definition of early norepinephrine initiation. Future studies should also investigate the impact of early norepinephrine use on long-term mortality, including the upcoming Crystalloid Liberal or Vasopressors Early Resuscitation in Sepsis trial (35).

\section{Sedation and Analgesia}

Nonsedation or Light Sedation in Critically Ill, Mechanically Ventilated Patients. The Nonsedation or Light Sedation in Critically Ill, Mechanically Ventilated Patients (NONSEDA) trial was a multicenter, randomized, nonblinded study evaluating light sedation versus nonsedation in mechanically ventilated patients (9). Patients were randomized to receive either nonsedation or light sedation, defined as a Richmond Agitation-Sedation Scale (RASS) -2 to -3 . Patients in 
the light sedation group received propofol for the first 48 hours of mechanical ventilation then transitioned to a continuous midazolam infusion per study protocol.

There was no difference in all-cause 90-day mortality between the nonsedation and light sedation groups (42.4\% vs $37.0 \%$; $95 \% \mathrm{CI},-2.2$ to 12.2 ; $p=0.65)$. Secondary outcomes included delirium-free days, days without mechanical ventilation, and occurrence of thromboembolic events, of which no significant differences were found. Within the nonsedation group, $27.0 \%$ required sedation on day 1 and $38.4 \%$ received sedation at some time during their ICU stay, with delirium being cited as the most frequent reason. The safety outcome of self-extubation requiring reintubation within 24 hours was more common in the nonsedation group versus light sedation group $(8.9 \%$ vs $4.0 \%, p=0.01$ ).

Sedation in ventilated patients has been an important topic, yet ideal standard definitions for light sedation and established protocols are not commonplace. A meta-analysis of 8,001 mechanically ventilated patients found a significantly higher mortality risk with those receiving deeper levels of sedation $(p=0.003)$. Those with lighter sedation were at risk of agitation-related adverse events such as unintentional extubation ( $p=0.002)$; however, no difference in delirium was identified (36). The Pain, Agitation/Sedation, Delirium, Immobility, and Sleep (PADIS) guidelines favors nonbenzodiazepines for sedation owing to shorter time to extubation (37). Light sedation is recommended over deep sedation; however, the PADIS guidelines do not specifically address nonsedation strategies in mechanically ventilated patients.

Prior to the NONSEDA trial, Strøm et al (38) evaluated a nonsedation strategy in a single-site medical/ surgical ICU. The investigators randomized 140 mechanically ventilated patients to receive either nonsedation or sedation protocols. Converse to the NONSEDA trial, Strøm et al (38) found a significant improvement in length of ventilation, ICU length of stay and hospital length of stay when the nonsedation strategy was used. Possible reasons the NONSEDA trial did not replicate these results include the similar RASS scores between groups and the high prevalence of sedation utilization in the nonsedation group. The results of the NONSEDA trial suggest that a nonsedation strategy is noninferior to light sedation and that light sedation may be a safer strategy to prevent harmful adverse effects such as self-extubation. Nonsedation may be appropriate for a select population but further trials are needed.

Dexmedetomidine for Reduction of Atrial Fibrillation and Delirium After Cardiac Surgery: A Randomized Placebo-Controlled Trial. Dexmedetomidinepossessessedativeandsympatholytic properties with minimal respiratory depression (10). Previous data regarding use of dexmedetomidine in cardiac surgery to reduce atrial fibrillation (AF) have been inconclusive $(39,40)$. Dexmedetomidine has been shown to reduce delirium postcardiac surgery; however, guidelines do not mention the use of dexmedetomidine in this patient population $(41,42)$. Guideline recommendations support the use of propofol over benzodiazepines for intubated patients and dexmedetomidine use in mechanically ventilated patients when agitation is inhibiting weaning of sedation and extubation; however, recommend against use of dexmedetomidine to prevent delirium (37).

Turan et al (10) conducted a multicenter, randomized, placebo-controlled trial to evaluate dexmedetomidine's effect on a coprimary outcome of atrial arrhythmia and delirium in adult patients undergoing cardiac surgery with cardiopulmonary bypass and heart rate greater than 50 beats/min. Secondary outcomes included kidney function, incisional pain, bradycardia and hypotension requiring treatment, stroke, myocardial infarction, venous thromboembolism, surgical site infection, and mortality. Dexmedetomidine was started preincision at $0.1 \mu \mathrm{g} / \mathrm{kg} / \mathrm{hr}$ and escalated to $0.2 \mu \mathrm{g} / \mathrm{kg} / \mathrm{hr}$ at bypass termination. Postsurgery, the infusion was increased to $0.4 \mu \mathrm{g} / \mathrm{kg} / \mathrm{hr}$ and continued for 24 hours. Managing providers reduced the dose if hemodynamics necessitated, and additional sedatives, such as propofol and benzodiazepines, were used based on discretion.

A total of 400 and 398 patients were randomized in the dexmedetomidine and placebo groups, respectively, when the trial was terminated early. No difference in postoperative AF was observed in patients receiving dexmedetomidine compared with placebo (30\% vs $34 \%$; RR, $0.91 ; p=0.34$ ) and there was a nonsignificant increase in delirium incidence among patients in the dexmedetomidine group (17\% vs $12 \%$; $\mathrm{RR}, 1.48 ; p=0.026)$. More clinically significant hypotension was observed in the dexmedetomidine group (57\% vs $36 \%$ ) and in a post hoc analysis, delirium was more likely in patients with clinically significant 
hypotension $(p=0.009)$. These findings were consistent across sites; patient demographics and measures were relatively homogenous. Amiodarone prophylaxis was prohibited and beta-blocker doses were not reported. Additionally, benzodiazepine use was not described.

Turan et al (10) demonstrated dexmedetomidine failed to reduce incidence of $\mathrm{AF}$ and observed increased hypotension and delirium, even at relatively low doses. Based on lack of evidence to support dexmedetomidine to reduce AF and finding increased delirium postcardiac surgery in this appropriately powered trial, its use should be reserved for patients requiring light sedation.

\section{Stroke}

Endovascular Thrombectomy With or Without IV Alteplase in Acute Stroke (DIRECT-MT). DIRECT-MT was a prospective, randomized, openlabel trial of 656 patients with acute ischemic stroke (12). Adult patients with a large vessel occlusion and neurologic deficit, indicated with National Institute of Health Stroke Scale (NIHSS) of at least two, who could also be treated with alteplase within 4.5 hours of symptom onset were included in the trial. Patients with baseline disability, defined as score greater than 2 on modified Rankin Scale (mRS) or contraindication to alteplase were excluded. Patients were randomized to either thrombectomy alone $(n=327)$ or combination thrombectomy plus alteplase, dosed at $0.9 \mathrm{mg} / \mathrm{kg}$ to a maximum of $90 \mathrm{mg}(n=329)$.

Patient characteristics at baseline were similar in both groups with a median NIHSS score of 17 . In an intent-to-treat analysis, the adjusted common OR for mRS score at 90 days was 1.07 (95\% CI, 0.81-1.40; $p=0.04)$ concluding thrombectomy alone was noninferior to combination thrombectomy. Mortality, serious adverse events, and procedural complications were similar between groups.

Retrospective studies and meta-analyses have produced conflicting results on benefits of IV thrombolytics prior to thrombectomy; thus, this is the first RCT to show noninferiority of thrombectomy alone over combination therapy (43-46). Despite achieving successful reperfusion in most patients, only $\sim 36 \%$ of patients had mRS of $0-2$ at 90 days displaying the impact of multiple factors on outcomes.

Limitations of this study are primarily related to practice patterns in China differing to those in the
United States. Time from triage to randomization was longer due to workflow (e.g., fewer prehospital stroke activations and lengthy discussions with multiple family members regarding informed consent of receiving alteplase). Thus, median time from symptom onset to randomization was almost 170 minutes, significantly higher than a prior thrombectomy trial (47). Additionally, the causes of stroke differ in Asian versus non-Asian populations, making these results less generalizable.

Alternative thrombolytics, such as tenecteplase, have shown potentially improved outcomes. Encouraging early reperfusion data was observed with tenecteplase in a separate RCT that compared alteplase to tenecteplase prior to thrombectomy (47). Thus, similar trial design with tenecteplase may produce more compelling data for the combination therapy given the ease of administration and promising reperfusion data (47). Given the adverse events, cost, and strict exclusion criteria surrounding IV alteplase, it may be reasonable to consider thrombectomy alone for patients in whom risks of thrombolytic therapy outweigh the benefits.

\section{CONCLUSIONS}

This clinical review provides perspectives on influential critical care pharmacotherapy publications in 2020 along with insight on clinical practice impact. Limitations of the article include the possibility of missing relevant literature among unreviewed journals as well as future considerations for ongoing publications surrounding sepsis, sedation, COVID-19, and stroke. Further trials are needed to answer numerous clinical questions surrounding these highly prevalent disease states.

\section{ACKNOWLEDGMENTS}

Other members of the Clinical Pharmacy and Pharmacology Pharmacotherapy Literature Update group are acknowledged for their contribution: George Abdallah, Beth Israel Deaconess; Tori Adams, Northwestern Memorial; Diana Altshuler, NYU Langone; Mahmoud Ammar, Yale; Brooke Barlow, U.K. Healthcare; Alyson Basting, IU Health Arnett; Laura Brickett, Geisinger Med Center; Judah Brown, Thomas Jefferson University Hospital; Lisa Burry, Mount Sinai; Tyler Chanas, Vidant Med Center; Laura Coles, Wake Forest; Patrick Costello, 
University of Chicago; Aubrey Defayette, Roswell Park Comprehensive Cancer Center; Payal Desai, Morristown Medical Center; Elisabeth Donahey, Lexicomp; Chris Droege, UCMC Cincinnati; Daniela Fernandez, Nova Southeastern University; Mallory Fiorenza, Lee Memorial; David Gagnon, Maine Med Center; Gabrielle Gibson, BarnesJewish; Brian Gilbert, Wesley Med Center; Kasey Greathouse, Northwestern Memorial; Jennifer Hanify, Holmes Regional; Mai Hashhoush, Michelle Henninger, Cleveland Clinic; Olivia Henton, Ohio Health Riverside Methodist; Benjamin Hohlfelder, Cleveland Clinic; Randy Hollins, Tufts; Ah Hyun Jun, Northside Hospital Cherokee; Brian Kopp, Banner-UMC Tucson; Kinsey Kowalski, Ochsner Med Center; Steven Lemieux, Yale; Carolyn Magee Bell, MUSC; Chris Miller, St Anthony Hospital; Megan Moore, Sanford Medical Center; Andrea Newsome, Augusta University Medical Center; Bill Olney, U.K. Healthcare; Jaimini Patel, University of Michigan; Sarah Peppard, Concordia University; Haley Peters, IU Health Methodist; Caitlin Pfaff, UC Health; Carolyn Philpott, University of Cincinnati Medical Center; Angela Plewa-Rusiecki, Stroger of Cook County; Nicole Reardon, Ocala Regional; Brianne Ritchie, CHI Health Lakeside Hospital; Ryan Rivosecchi, University of Pittsburgh Medical Center; Lauren Roller, Touro University California; Melissa Santibanez, Larkin U COP; Samantha Say, University of Virginia Medical Center; Mike Semanco, Lakeland Regional Health; Angela Slampak-Cindric, Geisinger Medical Center; William Tidwell, Vanderbilt; Rachel LaBianca Toler, Duke Regional; Megan Van Berkel Patel, Erlanger; Patrick Wieruszewski, Mayo Clinic Rochester; Corey Witenko, NY-Presbyterian; and Jason Yerke, Cleveland Clinic.

1 University of Kentucky, Lexington, $K Y$.

2 The University of Texas MD Anderson Cancer Center, Houston, TX.

3 Clinical Pharmacy Specialist in Critical Care and Nutrition Support, The University of Texas MD Anderson Cancer Center, Houston, TX.

4 Beth Israel Deaconess Medical Center, Boston, MA.

5 Advocate Christ Medical Center, Oak Lawn, IL.

6 OhioHealth Riverside Methodist Hospital, Columbus, $\mathrm{OH}$.

7 Froedtert and the Medical College of Wisconsin, Milwaukee, WI.

8 UPMC Pinnacle, Harrisburg, PA.
9 Northwestern Memorial Hospital, Chicago, IL.

10 Northwestern McGaw Medical Center, Chicago, IL.

11 Medical University of South Carolina, Charleston, SC.

The authors have disclosed that they do not have any potential conflicts of interest.

For information regarding this article, E-mail: Brittany.bissell@uky.edu

\section{REFERENCES}

1. Bastian H, Glasziou P, Chalmers I: Seventy-five trials and eleven systematic reviews a day: How will we ever keep up? PLoS Med 2010; 7:e1000326

2. Curran V, Matthews L, Fleet $L$, et al: A review of digital, social, and mobile technologies in health professional education. $J$ Contin Educ Health Prof 2017; 37:195-206

3. Turck CJ, Frazee E, Kram B, et al: Major publications in the critical care pharmacotherapy literature: February 2012 through February 2013. Am J Heal Pharm 2014; 71:68-77

4. Newsome AS, Bissell BD, Burry LD, et al: Major publications in critical care pharmacotherapy literature in 2018. J Crit Care 2019; 52:200-207

5. Horner D, Altshuler D, Droege C, et al: Major publications in the critical care pharmacotherapy literature: January-December 2016. J Crit Care 2018; 43:327-339

6. Condeni MS, Basting AT, Costello PG, et al: Major publications in the critical care pharmacotherapy literature: 2019. J Crit Care 2021; 62:197-205

7. Dellinger RP, Levy MM, Rhodes A, et al; Surviving Sepsis Campaign Guidelines Committee including The Pediatric Subgroup: Surviving sepsis campaign: International guidelines for management of severe sepsis and septic shock, 2012. Intensive Care Med 2013; 39:165-228

8. Fujii T, Luethi N, Young PJ, et al; VITAMINS Trial Investigators: Effect of vitamin $\mathrm{C}$, hydrocortisone, and thiamine vs hydrocortisone alone on time alive and free of vasopressor support among patients with septic shock: The VITAMINS randomized clinical trial. JAMA 2020; 323:423-431

9. Olsen HT, Nedergaard HK, Strøm T, et al: Nonsedation or light sedation in critically ill, mechanically ventilated patients. N Engl J Med 2020; 382:1103-1111

10. Turan A, Duncan A, Leung S, et al; DECADE Study Group: Dexmedetomidine for reduction of atrial fibrillation and delirium after cardiac surgery (DECADE): A randomised placebo-controlled trial. Lancet 2020; 396:177-185

11. Wang $Y$, Zhang D, Du G, et al: Remdesivir in adults with severe COVID-19: A randomised, double-blind, placebo-controlled, multicentre trial. Lancet 2020; 395:1569-1578

12. Yang $P$, Zhang $Y$, Zhang L, et al; DIRECT-MT Investigators: Endovascular thrombectomy with or without intravenous alteplase in acute stroke. N Engl J Med 2020; 382:1981-1993

13. Li Y, Li H, Zhang D: Timing of norepinephrine initiation in patients with septic shock: A systematic review and metaanalysis. Crit Care 2020; 24:488

14. WHO Rapid Evidence Appraisal for COVID-19 Therapies (REACT) Working Group, Sterne JAC, Murthy S, et al: 
Association between administration of systemic corticosteroids and mortality among critically ill patients with COVID-19: A meta-analysis. JAMA 2020; 324:1330-1341

15. Beigel JH, Tomashek KM, Dodd LE, et al; ACTT-1 Study Group Members: Remdesivir for the treatment of Covid-19 - final report. N Engl J Med 2020; 383:1813-1826

16. Pan H, Peto R, Henao-Restrepo A-M, et al; WHO Solidarity Trial Consortium: Repurposed antiviral drugs for Covid-19 - Interim WHO solidarity trial results. N Engl J Med 2021; 384:497-511

17. Spinner CD, Gottlieb RL, Criner GJ, et al; GS-US-540-5774 Investigators: Effect of remdesivir vs standard care on clinical status at 11 days in patients with moderate COVID-19: A randomized clinical trial. JAMA 2020; 324:1048-1057

18. Goldman JD, Lye DCB, Hui DS, et al; GS-US-540-5773 Investigators: Remdesivir for 5 or 10 days in patients with severe Covid-19. N Engl J Med 2020; 383:1827-1837

19. Bhimraj A, Morgan RL, Shumaker AH, et al: Infectious Diseases Society of America guidelines on the treatment and management of patients with COVID-19. Clin Infect Dis 2020 Apr 27. [online ahead of print]

20. Alhazzani W, Møller MH, Arabi YM, et al: Surviving sepsis campaign: Guidelines on the management of critically ill adults with coronavirus disease 2019 (COVID-19). Crit Care Med 2020; 48:e440-e469

21. Lansbury L, Rodrigo C, Leonardi-Bee J, et al: Corticosteroids as adjunctive therapy in the treatment of influenza. Cochrane Database Syst Rev 2019; 2:CD010406

22. Li H, Chen C, Hu F, et al: Impact of corticosteroid therapy on outcomes of persons with SARS-CoV-2, SARS-CoV, or MERS-CoV infection: A systematic review and meta-analysis. Leukemia 2020; 34:1503-1511

23. RECOVERY Collaborative Group, Horby P, Lim WS, et al: Dexamethasone in hospitalized patients with Covid-19. N Engl J Med 2021; 384:693-704

24. Marik PE, Khangoora V, Rivera R, et al: Hydrocortisone, vitamin $\mathrm{C}$, and thiamine for the treatment of severe sepsis and septic shock: A retrospective before-after study. Chest 2017; 151:1229-1238

25. Moskowitz A, Huang DT, Hou PC, et al; ACTS Clinical Trial Investigators: Effect of ascorbic acid, corticosteroids, and thiamine on organ injury in septic shock: The ACTS randomized clinical trial. JAMA 2020; 324:642-650

26. Iglesias J, Vassallo AV, Patel VV, et al: Outcomes of metabolic resuscitation using ascorbic acid, thiamine, and glucocorticoids in the early treatment of sepsis: The ORANGES trial. Chest 2020; 158:164-173

27. Venkatesh B, Finfer S, Cohen J, et al; ADRENAL Trial Investigators and the Australian-New Zealand Intensive Care Society Clinical Trials Group: Adjunctive glucocorticoid therapy in patients with septic shock. N Engl J Med 2018; 378:797-808

28. Annane D, Sébille V, Charpentier C, et al: Effect of treatment with low doses of hydrocortisone and fludrocortisone on mortality in patients with septic shock. JAMA 2002; 288:862-871

29. Bai $X, Y u$ W, Ji W, et al: Early versus delayed administration of norepinephrine in patients with septic shock. Crit Care 2014; 18:532

30. Elbouhy MA, Soliman M, Gaber A, et al: Early use of norepinephrine improves survival in septic shock: Earlier than early. Arch Med Res 2019; 50:325-332
31. Colon Hidalgo D, Patel J, Masic D, et al: Delayed vasopressor initiation is associated with increased mortality in patients with septic shock. J Crit Care 2020; 55:145-148

32. Ospina-Tascón GA, Hernandez G, Alvarez I, et al: Effects of very early start of norepinephrine in patients with septic shock: A propensity score-based analysis. Crit Care 2020; 24:52

33. Rhodes A, Evans LE, Alhazzani W, et al: Surviving sepsis campaign: International guidelines for management of sepsis and septic shock: 2016. Intensive Care Med 2017; 43:304-377

34. Levy MM, Evans LE, Rhodes A: The surviving sepsis campaign bundle: 2018 update. Intensive Care Med 2018; 44:925-928

35. ClinicalTrials.gov: Crystalloid Liberal or Vasopressors Early Resuscitation in Sepsis. Available at: https://clinicaltrials.gov/ ct2/show/NCT03434028. Accessed January 15, 2021.

36. Long L, Ren S, Gong $Y$, et al: Different depths of sedation versus risk of delirium in adult mechanically ventilated patients: A systematic review and meta-analysis. PLoS One 2020; 15:e0236014

37. Devlin JW, Skrobik Y, Gélinas C, et al: Clinical practice guidelines for the prevention and management of pain, agitation/ sedation, delirium, immobility, and sleep disruption in adult patients in the ICU. Crit Care Med 2018; 46:e825-e873

38. Strøm T, Martinussen T, Toft P: A protocol of no sedation for critically ill patients receiving mechanical ventilation: $A$ randomised trial. Lancet 2010; 375:475-480

39. Liu Y, Zhang L, Wang S, et al: Dexmedetomidine reduces atrial fibrillation after adult cardiac surgery: A meta-analysis of randomized controlled trials. Am J Cardiovasc Drugs 2020; 20:271-281

40. Zhu Z, Zhou H, Ni Y, et al: Can dexmedetomidine reduce atrial fibrillation after cardiac surgery? A systematic review and meta-analysis. Drug Des Devel Ther 2018; 12:521-531

41. Likhvantsev VV, Landoni G, Grebenchikov OA, et al: Perioperative dexmedetomidine supplement decreases delirium incidence after adult cardiac surgery: A randomized, double-blind, controlled study. J Cardiothorac Vasc Anesth 2021; 35:449-457

42. Wu M, Liang Y, Dai Z, et al: Perioperative dexmedetomidine reduces delirium after cardiac surgery: A meta-analysis of randomized controlled trials. J Clin Anesth 2018; 50:33-42

43. Goyal N, Tsivgoulis G, Frei D, et al: Comparative safety and efficacy of combined IVT and MT with direct MT in large vessel occlusion. Neurology 2018; 90:e1274-e1282

44. Bellwald S, Weber R, Dobrocky T, et al: Direct mechanical intervention versus bridging therapy in stroke patients eligible for intravenous thrombolysis: A pooled analysis of 2 registries. Stroke 2017; 48:3282-3288

45. Wee CK, McAuliffe W, Phatouros CC, et al: Outcomes of endovascular thrombectomy with and without thrombolysis for acute large artery ischaemic stroke at a tertiary stroke centre. Cerebrovasc Dis Extra 2017; 7:95-102

46. Rai AT, Boo S, Buseman C, et al: Intravenous thrombolysis before endovascular therapy for large vessel strokes can lead to significantly higher hospital costs without improving outcomes. J Neurointerv Surg 2018; 10:17-21

47. Campbell BCV, Mitchell PJ, Churilov L, et al; EXTEND-IA TNK Investigators: Tenecteplase versus alteplase before thrombectomy for ischemic stroke. N Engl J Med 2018; 378:1573-1582 


\section{APPENDIX A: JOURNALS INCLUDED IN THE CLINICAL PHARMACY AND PHARMACOLOGY PHARMACOTHERAPY LITERATURE UPDATE REVIEW}

American Journal of Clinical Nutrition, American Journal of Emergency Medicine, American Journal of Health-System Pharmacy, American Journal of Respiratory and Critical Care Medicine, Anesthesia and Analgesia, Annals of Emergency Medicine, Annals of Intensive Care, Annals of Pharmacotherapy, Anesthesiology, CHEST, Circulation, Clinical
Infectious Diseases, Clinical Toxicology, Critical Care, Critical Care Explorations, Critical Care Medicine, Intensive Care Medicine, JAMA, Journal of Cardiothoracic and Vascular Anesthesia, Journal of Critical Care, Journal of Intensive Care Medicine, Journal of Neurotrauma, Journal of the American College of Cardiology, Journal of Trauma and Acute Care Surgery, Journal of Parenteral and Enteral Nutrition, Lancet, Lancet Infectious Diseases, Lancet Neurology, Lancet Respiratory Medicine, Neurocritical Care, New England Journal of Medicine, Pharmacotherapy, Resuscitation, Shock, and Stroke. 